\title{
Kernos
}

Revue internationale et pluridisciplinaire de religion grecque antique

$17 \mid 2004$

Varia

\section{André MOTTE, Charles-Marie TERnEs (éds), Dieux, fêtes, sacré dans la Grèce et la Rome antiques. Actes du Colloque tenu à Luxembourg du 24 au 26 octobre 1999}

\section{Philippe-Alexandre Broder}

\section{(2) OpenEdition}

\section{Édition électronique}

URL : http://journals.openedition.org/kernos/1493

DOI : 10.4000/kernos.1493

ISSN : 2034-7871

\section{Éditeur}

Centre international d'étude de la religion grecque antique

\section{Édition imprimée}

Date de publication : 1 janvier 2004

ISSN : 0776-3824

\section{Référence électronique}

Philippe-Alexandre Broder, «André мотте, Charles-Marie ternes (éds), Dieux, fêtes, sacré dans la Grèce et la Rome antiques. Actes du Colloque tenu à Luxembourg du 24 au 26 octobre 1999 », Kernos [En ligne], 17| 2004, mis en ligne le 16 juin 2011, consulté le 21 décembre 2020. URL : http:// journals.openedition.org/kernos/1493; DOI : https://doi.org/10.4000/kernos.1493 
sive des cas étudiés. L'A. reprend les trois axes principaux de sa réflexion - les finances sacrées, le territoire sacré et l'administration religieuse -, mais en les abordant par le biais d'un questionnement transversal en deux volets, déjà effleurés dans le premier chapitre : est-il pertinent de jouer sur une distinction stricte entre sanctuaires civiques des cités de la côte et sanctuaires ruraux de l'Anatolie centrale et orientale - en faisant notamment appel à des notions floues comme l'urbanisation ou l'hellénisation ? faut-il opposer la Grèce continentale et l'Asie Mineure dans l'évaluation de l'autorité sacerdotale? La réponse aux deux questions est très nuancée, mais globalement négative. Soulignons que les vingt-cinq pages consacrées à la question des prêtrises est selon moi ce que l'on a écrit de meilleur sur le sujet. Et l'on se prend à rêver d'un autre livre de l'A. qui offrirait enfin le travail d'ensemble sur les prêtrises grecques dont on a tant besoin...

Deux appendices, l'un sur une inscription de Sardes beaucoup discutée (I.Sardis VII, 1), l'autre sur l'asylie des sanctuaires micrasiatiques sous autorité romaine, précèdent une copieuse bibliographie multilingue qui a adéquatement nourri l'ensemble du parcours. Les index sont également très fournis et l'on saura gré à l'A. d'avoir présenté tant et tant de textes épigraphiques avec leur traduction et un commentaire informé et précis. Ce livre est un pas important dans la direction d'une évaluation plus nuancée des intrications complexes entre les cultes, la piété, le pouvoir et l'argent.

Vinciane Pirenne-Delforge (FNRS - Université de Liège)

André MotTe, Charles-Marie Ternes (éds), Dieux, fêtes, sacré dans la Grèce et la Rome antiques. Actes du Colloque tenu à Luxembourg du 24 au 26 octobre 1999, Turnhout, Brepols, 2003. 1 vol. $16 \times 24$ cm, 306 p. (Homo Religiosus. Série II, 2). ISBN : 2-503-51222-4.

Le second volume de la seconde série de la collection Homo Religiosus est la publication des actes d'un colloque qui s'est tenu au centre Jean XXXII de Luxembourg sur le thème de la fête. Les organisateurs ont privilégié trois axes. D'abord, une approche comparatiste entre les cités grecques et Rome, cité et empire, qui s'ouvre parfois aux religions orientales. Ensuite, une approche diachronique, dans la longue durée, de l'époque minoenne à la christianisation de l'empire romain. Enfin, la recherche d'une synthèse qui s'appuie sur des exemples concrets de fête. Malgré cet effort, il est nécessaire de résumer brièvement chaque communication afin que le lecteur sache quelles informations y trouver et quelles thèses sont avancées. Six articles concernent la Grèce, sept concernent Rome et le dernier retrace l'historiographie de la question. Seuls les articles de G. Capdeville, I. Tassignon et A. Motte sont suivis d'une bibliographie et le volume contient une présentation des auteurs, pas d'index.

L'article de R. Turcan inaugure les communications portant sur la Grèce et sert d'introduction à cette partie. Il compare l'initiation (télétê) et la fête (béortè). L'initiation est une fête dont la particularité n'est pas l'absence de joie mais la permanence du nouvel état vécu dans la fête. G. Capdeville étudie le culte du dieu Velchanos en Crète et à Chypre. Il établit une continuité de la période minoenne à l'époque impériale d'un dieu souverain associé à l'arbre. D. Aubriot propose de comparer la façon dont la fête est traitée dans la poésie épique d'Homère et dans la poésie lyrique de Pindare. Elle étudie surtout la mise en scène poétique d'une fête d'Apollon parallèle au massacre des prétendants dans l'Odyssée et met en valeur le procédé littéraire de compression des lieux, des temps et des statuts qu'elle considère comme un élément essentiel de la fête. I. Tassignon étudie la fête de Dionysos Katagôgios dans plusieurs cités d'Asie 
Nineure. Les Katagôgia marquent le retour d'exil d'un dieu lésé par la cité qu'il faut se concilier avant de célébrer son triomphe joyeux. L'origine hittite de cette fête expliquerait son caractère local. Fr. Dunant étudie les fondations de fêtes nouvelles dans les cités d'Asie Mineure à l'époque hellénistique. Ces fêtes ont bien un caractère politique mais elles sont surtout le signe d'une piété collective et individuelle tout à fait traditionnelle. Enfin, A. Motte esquisse une synthèse sur la fête grecque dont il affirme l'unité, au-delà de la diversité des fêtes. Il insiste sur la communauté du panthéon et des rites, la présence tempotaire de la divinité et le caractère spectaculaire et joyeux des fêtes grecques.

La partie consacrée à Rome s'ouvre avec l'article de D. Briquel qui étudie la personnalité du dieu Voltumna auquel les Étrusques rendaient un culte fédéral. Il l'identifie au dieu romain Vertumnus, dieu des commencements comme Janus, mais également « dieu-cadre ", dieu principal des Étrusques structurés par le système duodécimal, dieu présidant au renouvellement du temps (douze mois) et de l'espace social (douze cités). J. Champeaux, dans une synthèse parallèle à celle d'A. Motte, étudie la participation populaire dans les fêtes publiques du calendrier romain contre une historiographie qui oppose les fêtes grecques où les citoyens participent en foule et les fêtes romaines où l'aristocratie serait le seul agent du culte. L'A. établit une typologie pour les fêtes archä̈ques, allant des fêtes où le peuple est un simple spectateur aux fêtes où il est le principal acteur, et discerne une évolution vers un accroissement de la participation populaire aux fêtes publiques jusqu'à l'apogée des Jeux Séculaires augustéens. Y. Lehmann reprend l'étude du calendrier des fêtes publiques romaines mais pour observer comment un auteur, Varron, présente à un moment historique, le $\mathrm{I}^{\mathrm{er}} \mathrm{s}$. ap. J.-C., ces fêtes publiques. Varron choisit les fêtes qu'il répertorie, élabore des interprétations rationalisantes qui contredisent parfois les autres sources. Ch. Guittard s'intéresse aux prières prononcées lors des Jeux Séculaires augustéens et connues par les sources épigraphiques. Il restitue le rôle de chacun des acteurs (Auguste, Agrippa, les cent-dix matrones, Horace) et met en évidence une évolution de la piété romaine à traver's ces prières : l'insistance sur l'acceptation des demandes et l'agenouillement, le recours à des formules archaïsantes et la mise en parallèle de la cité et de l'empereur. M. Gschaid étudie les cultes des provinces romaines des Alpes orientales à l'époque impériale à partir des inscriptions, dédicaces ou inscriptions honorifiques, célébrant parfois la victoire militaire d'une légion du limes. L'auteur insiste sur la prééminence des dieux romains et du culte impérial, même si des syncrétismes sont visibles. Les deux agents principaux de la romanisation furent d'une part les colonies et municipes (surtout le culte impérial), d'autre part les légions stationnées en garnison (culte public lors des Volcanalia, culte militaire du Genius legionis, voire culte oriental de Mithra). Th. P. Osborne voit dans l'Apocalypse de Jean de Patmos un pamphlet crypté émanant de milieux juifs ou judéo-chrétiens, dans le contexte de la destruction de Jérusalem en 70 ap. J.-C. Jean ferait allusion à la destruction du Temple par Rome, identifiée à la Bête et caractérisée par le culte des images divines, pas seulement impériales. Il proposerait à ses coreligionnaires un exil géographique hors de l'empire, voire un exil intérieur dans le refus d'accepter son fonctionnement et ses valeurs. J. Ries reprend un article de R. Turcan sur le culte impérial d'Auguste à Constantin, culte des souverains et culte imposé par les souverains, qu'il confronte aux sources chrétiennes, principalement les Pères de l'Église. Selon J. Ries, le culte impérial a évolué avec la crise du III s. ap. J.-C., au moment de l'essor et de l'institutionnalisation du christianisme. Les Chrétiens du Irr s. s'opposaient moins à l'empereur qu'au paganisme et les persécutions n'auraient été qu'une «tragique méprise». Enfin, N. Spineto confronte les théories modernes de la fête, principalement issues de l'école ritualiste de Cambridge 
et centrées sur le crime du sacrifice, fondateur du lien social, et de l'école sociologique française qui insiste sur le rôle de la fête comme régénération de l'unité de la communauté mais aussi de ses hiérarchies. L'auteur insiste sur une évolution fondamentale de la fête: alors que les fête anciennes, a fortiori antiques, avaient une fonction religieuse, les fêtes modernes sont profanes et tendent à se confondre avec les loisirs et les vacances.

Ces contributions sont donc très diverses, tant par la période étudiée, leurs sources, les aspects pris en compte, que par leur degré de généralité. Cet ensemble a l'avantage, dans ses limites mêmes, de bien mettre en évidence les problèmes et les enjeux de l'étude des fêtes grecques et romaines.

D'abord, la définition de la fête pose problème. Si certaines contributions traitent assurément de la fête, par exemple $\mathrm{J}$. Champeaux dans un article très utile sur les fêtes publiques romaines ou I. Tassignon sur une fête particulière, dans d'autres articles le thème de la fête n'est pas aussi évident. Par exemple, G. Capdeville reconnaît que les informations sur le culte sont très minces. C'est également le cas pour le culte panétrusque de Voltumna étudié par D. Briquel. La fête comportait-elle des concours? Tout cela reste incertain. Les auteurs sont contraints par leurs sources d'étudier plutôt la personnalité d'une divinité, les mythes où elle apparaît. Nous pouvons faire une constatation plus générale : les sources sur les fêtes sont rares, même dans l'ensemble des sources sur la religion. Un culte est généralement attesté par une dédicace, un monument (de la simple statue au sanctuaire), le dieu est parfois l'acteur d'un mythe mais le programme festif est moins souvent connu, et rarement complètement. Les inscriptions développées des cités d'Asie Mineure à l'époque hellénistique sont excep. tionnelles.

Parallèlement à leur rareté, les sources sur les fêtes sont extrêmement dispersées dans le temps et allusives, c'est-à-dire que le travail habituel de l'historien qui consiste à transformer un document en source pour l'étude d'un sujet est particulièrement visible et fragile. L'excellent article d'I. Tassignon en est un exemple. Le nom Katagôgia apparaît dans des inscriptions hellénistiques, sans que le contenu de la fête soit décrit ni la divinité nommée dans tous les cas. C'est l'historien qui pose comme hypothèse de travail que la divinité est la même, avec vraisemblance. Le contenu de la fête est restitué à partir de l'analyse de katagein et de sources de types et d'époques extrêmement divers où le mot n'apparaît pas et qui sont associées par l'historien : céramique attique à figures noires archaïque, mythes rapportés par des sources d'époque impériale comme les actes de saint Timothée.

Même quand des éléments du culte sont connus, peut-on parler de fête, voire de fête publique? Le bouquetin d'une image de la série de Velchanos ou la ronde de femmes peuvent être les éléments du culte en général mais font-ils partie du programme d'une fête? La fête n'est-elle pas un événement réglé par une loi, écrite ou non, donc communautaire même si elle n'est pas célébrée collectivement ? La publication de la communication de V. Pirenne-Delforge sur le vocabulaire de la fête chez Pausanias - évoquée dans l'introduction - permettra peut-être d'avancer dans la résolution de ce problème central, en distinguant ce qui, parmi les rites et les cérémonies, est appelé béortè. 